\title{
AS REPRESENTAÇÕES NA IMPRENSA DE PRÁTICAS CÍVICO- PATRIÓTICAS EM INSTITUIÇÕES ESCOLARES DE MINAS GERAIS (BRASIL) NA PRIMEIRA METADE DO SÉCULO XX
}

\author{
Giseli Cristina do Vale Gatti ${ }^{1}$ \\ Décio Gatti Júnior ${ }^{2}$
}

\begin{abstract}
Resumo
Trata-se da apresentação de resultados de pesquisa no âmbito da História da Educação, cujo objeto privilegiado foi a relação estabelecida entre os eventos cívico-patrióticos promovidos por duas instituições escolares do Ensino Secundário, nas cidades de Uberaba e de Uberlândia, em Minas Gerais (Brasil), durante a primeira metade do Século XX, com relação às representações veiculadas pela imprensa de ambas as localidades. Em termos de aportes teóricos podem ser citados Nóvoa (1997), Escolano Benito (1998), Souza (1999), Bastos (2002), Bencostta (2006), Cândido (2007) etc. Buscou-se as notícias veiculadas pela imprensa local em ambos os municípios, com a constatação da ênfase nos eventos cívicos promovidos pelas escolas, nos quais eram envolvidas as populações locais, o que conferia centralidade destas atividades na vida das escolas, mas, também, na vida das cidades. As fontes de pesquisa incluíram jornais de época, documentação manuscrita e impressa e iconografia. Os resultados apontam para a convergência dos ideais republicanos de formação da cidadania e os eventos cívico-patrióticos efetivados pelas instituições escolares, com grande participação popular e largamente noticiados pela imprensa local em ambas as cidades.
\end{abstract}

Palavras-chave: Imprensa. Escola. Patriotismo. Civismo. Minas Gerais.

\section{PRESS REPRESENTATIONS OF CIVIC-PATRIOTIC PRACTICES IN SCHOOL INSTITUTIONS OF MINAS GERAIS (BRAZIL) IN THE FIRST HALF OF THE 20TH CENTURY}

\begin{abstract}
This paper presents the results of research in History of Education, focusing on the relationship established between the civic-patriotic events promoted by two secondary school institutions in Uberaba and Uberlândia, two cities in the state of Minas Gerais (Brazil), in the first half of the twentieth century, and representation of these events in the local public press. The theoretical framework for this analysis includes Nóvoa (1997), Escolano Benito (1998), Souza (1999), Bastos (2002), Bencostta (2006), and Cândido (2007), among others. News reports published by the local press in both municipal areas were investigated, which revealed an emphasis on the civic events promoted by the schools, involving local populations. This made for the centrality of these activities in the life of the schools and in the life of the cities. Research sources included newspapers of that time, written and printed documentation, and iconography. Results indicate convergence of
\end{abstract}


republican ideals of training in citizenship and the civic-patriotic events carried out by the school institutions, with extensive community participation widely reported by the local press in both cities.

Keywords: Press. School. Patriotism. Civic virtue. Minas Gerais.

\section{LAS REPRESENTACIONES EN LA PRENSA DE PRÁCTICAS CÍVICO-PATRIÓTICAS EN INSTITUCIONES ESCOLARES DE MINAS GERAIS (BRASIL) EN LA PRIMERA MITAD DE SIGLO XX}

\section{Resumen}

Se trata de la presentación de resultados de investigación en el ámbito de la Historia de la Educación, cuyo objeto privilegiado fue la relación establecida entre los eventos cívicopatrióticos promovido por dos instituciones escolares de Enseñanza Secundaria, en las ciudades de Uberaba y de Uberlândia, en Minas Gerais (Brasil), durante la primera mitad del siglo XX, con relación a las representaciones vehiculadas por la prensa de ambas localidades. En términos de aportes teóricos pueden ser citados Nóvoa (1997), Escolano Benito (1998), Souza (1999), Bastos (2002), Bencostta (2006), Cândido (2007) etc. Se buscaron las noticias vehiculadas por la prensa local en ambos municipios, con la constatación del énfasis en los eventos cívicos promovidos por las escuelas, en los cuales eran envueltas las poblaciones locales, lo que daba centralidad a estas actividades en la vida de las escuelas, así como en la vida de las ciudades. Las fuentes de investigación incluían periódicos de época, documentación manuscrita, impresa e iconográfica. Los resultados apuntan para la convergencia de los ideales republicanos de formación de la ciudadanía y los eventos cívico-patrióticos realizados por las instituciones escolares, con gran participación popular y largamente noticiados por la prensa local en ambas ciudades.

Palabras clave: Prensa. Escuela. Patriotismo. Civismo. Minas Gerais.

\section{INTRODUÇÃO}

Este artigo tem por objetivo promover a análise das representações dos eventos cívico-patrióticos realizados no âmbito do ensino secundário, por meio do exame das notícias veiculadas na imprensa de duas importantes cidades brasileiras localizadas no Estado de Minas Gerais, a saber: Uberaba e Uberlândia.

É importante mencionar que as notícias e demais textos e imagens publicados pela imprensa nas diferentes localidades têm sido uma fonte muito importante no desenvolvimento da pesquisa no campo da História da Educação. Nesse sentido, a imprensa tornou-se um instrumento de referência para a compreensão e para a apreensão de fatos ligados à história educacional, fornecendo indícios que podem contribuir para entendimento 
das ideias pedagógicas disseminadas em determinado período, mas também para compreender a importância da escola em determinados contextos políticos e sociais.

Ao eleger duas escolas localizadas na região do Triângulo Mineiro, o Ginásio Mineiro de Uberlândia e o Ginásio Triângulo Mineiro de Uberaba, busca-se compreender, principalmente, por meio dos jornais de época, como esses festejos cívicos repercutiam no imaginário social. Tomando-se o novo contexto republicano no interior do recorte da investigação, percebe-se a preocupação em instruir esse novo sujeito social. Assim, a escola torna-se uma peça chave para a difusão dos novos ideais republicanos de Ordem e Progresso e para que tal objetivo fosse alcançado era necessário disseminar valores morais e não apenas o conhecimento científico.

Depreende-se, então, que os eventos cívico-patrióticos faziam parte do currículo da escola e eram atividades que congregavam alunos, professores e direção, pois eram manifestações culturais que traziam identidade à instituição escolar. As atividades cívicopatrióticas davam visibilidade às escolas, evidenciando disciplina e excelência formativa dos estabelecimentos de ensino e da educação neles ministrada, mas, também, reforçavam o sentimento cívico/patriótico e ajudavam a dar identidade ao novo contexto político brasileiro. Destaca-se, nesse sentido, a presença marcante da imprensa cobrindo essas festividades cívicas, demonstrando claramente o ímpeto de valorizar não só os preceitos da nova ordem política, mas também enaltecer a participação dos alunos nas festividades, apontando-os como exemplos de civilidade e de patriotismo.

Neste artigo, a exposição está dividida em três partes. Na primeira, abordam-se os aspectos conceituais em torno da relação entre Imprensa e Educação. Na segunda parte, também de caráter conceitual, trata-se dos eventos cívico-patrióticos e sua relação com a educação escolar. Na terceira e última parte, examina-se o caso concreto de duas instituições escolares, localizadas em Uberaba e em Uberlândia, que, por meio de suas práticas, enredavam a cidade em momentos de civismo e de patriotismo largamente cobertos pela imprensa local, com mobilização de contingentes populacionais significativos. Encerra-se a exposição com algumas considerações finais.

\section{A RELAÇÃO ENTRE IMPRENSA E EDUCAÇÃO}

Nas pesquisas desenvolvidas no campo da História da Educação têm se destacado como fonte documental valiosa, a imprensa, pois, por meio dela, tem sido possível encontrar elementos importantes que não estariam presentes em outra fonte documental. Nas notícias veiculadas pela imprensa, no que diz respeito ao contexto educacional, é possível encontrar artigos importantes relacionados à necessidade de instrução escolar, artigos publicados por professores que lecionavam nas escolas sobre os mais variados temas, divulgação de nomes de alunos que conseguiam passar em vestibulares para o ensino superior, chamadas para 
festividades a serem promovidas pela escola, campeonatos estudantis, anúncios de fundação de escolas, entre outras. Na realização de pesquisa no âmbito da História da Educação percebe-se que as notícias educacionais eram veiculadas muito fortemente nesse meio de comunicação. Segundo António Nóvoa,

\begin{abstract}
A imprensa é, provavelmente, o local que facilita um melhor conhecimento das realidades educativas, uma vez que aqui se manifestam, de um ou outro modo, o conjunto de problemas desta área. É difícil imaginar um meio mais útil para compreender as relações entre teoria e a prática, entre projetos e as realidades, entre a tradição e a inovação. São as características próprias da imprensa (a proximidade em relação ao acontecimento, o caráter fugaz e polêmico, a vontade de intervir na realidade) que lhe conferem este estatuto único e insubstituível como fonte para o estudo histórico e sociológico da educação e da pedagogia. (NÓVOA, 1997, p. 31).
\end{abstract}

Percebe-se, assim, a importância de recorrermos à imprensa como uma fonte possível de ser utilizada, com o intuito de buscarmos construir interpretações no que tange ao modelo educacional veiculado em um determinado período e localidade e como esse importante meio de comunicação influencia o imaginário de uma sociedade. Pode-se afirmar então, que essa fonte documental é muito significativa, uma vez que ela é partícipe da construção de um processo histórico, pois, por meio de seus registros, é possível perceber o cotidiano de uma cidade em determinado período, o que oportuniza, desta maneira, apreender os movimentos que emanam dessa sociedade, em seu contexto político, econômico, social e cultural. $\mathrm{O}$ fato é que a imprensa é presença marcante em todas as manifestações que giram em torno de uma sociedade. Vidal e Camargo (1992) destacam ainda que os jornais possibilitam a

[...] leitura de manifestações contemporâneas aos acontecimentos. Desta maneira,
realizamos uma aproximação do momento de estudo não pela fala de historiadores
da educação, mas pelos discursos emitidos na época. Em lugar do grande quadro
explicativo da História, da grande síntese que para ser efetuada desconhece
detalhes e matizes, lidamos com a pluralidade: as diversas falas colorem a
compreensão do período e indicam lutas diferenciadas, muitas vezes
irrecuperáveis no discurso homogêneo do historiador de grandes quadros,
fazendo-nos recuperar vieses que ficaram perdidos nas análises historiográficas
posteriores. Tanto o discurso das grandes análises, quanto a fala dos agentes
deslocada no tempo, por exemplo a apreciação de um educador sobre sua atuação
passada, ocultam elementos que, na época da publicação das revistas, eram
preocupações correntes, e depois foram esquecidos, obliterados por outras
questões. (VIDAL; CAMARGO, 1992, p. 408).

Ao nos debruçarmos sobre os registros da imprensa é possível encontrar indícios daquilo que se passava no campo educacional, ou seja, como se dava o funcionamento de suas estruturas escolares, as tendências pedagógicas, os discursos que se faziam em prol da educação, como a política influenciava os conteúdos a serem ensinados nesse espaço escolar. Esses elementos tornam-se valiosos quando se procura pesquisar a História da Educação, pois os registros da imprensa permitem essa aproximação da realidade de um passado. Interessante 
ainda destacar que a imprensa, embora importante para o desenvolvimento de pesquisas, não é um elemento neutro. Nessa perspectiva, Melo (1994) afirma que:

[...] os meios de comunicação coletiva, através dos quais as mensagens jornalísticas penetram na sociedade, bem como os demais meios de reprodução simbólica, são 'aparatos ideológicos', funcionando, se não monoliticamente atrelados ao Estado, [...] pelo menos atuando como uma 'indústria da consciência', [...] influenciando pessoas, comovendo grupos, mobilizando comunidades, dentro das contradições que marcam as sociedades. São, portanto, veículos que se movem na direção que lhes é dada pelas forças sociais que os controlam e que refletem também as contradições inerentes às estruturas societárias em que existe. (MELO, 1994, p. 20).

Segundo Bastos (2002), a imprensa é um dispositivo privilegiado para forjar o sujeito/cidadão, uma vez que tem a necessidade de informar sobre fatos, opiniões e acontecimentos. Podemos inferir a partir da afirmação de Bastos que a imprensa é um instrumento de veiculação de interesses e de formação de opinião e que certamente atua na vida social e histórica de uma comunidade. Entretanto, não deixa de ser importante para nós pesquisadores, pois, por meio dos jornais, podemos descortinar lacunas do campo educacional, que outras fontes documentais não dão conta. Certamente, é um instrumento que nos privilegia, pois é uma forma de buscarmos possíveis interpretações sobre o cotidiano educacional, o qual nos possibilita perceber as manobras e discursos em prol da educação, sendo esse o elemento essencial para formar um novo indivíduo, ou seja, o sujeito civilizado, disciplinado e que traga consigo os valores patrióticos, tônica que está presente entre o final do Século XIX e, pelo menos, a primeira metade do Século XX.

\section{O COTIDIANO ESCOLAR E OS EVENTOS CÍVICO-PATRIÓTICOS}

Cabe refletir ainda sobre a ideia de espaço escolar, na perspectiva apontada por Escolano Benito (1998, p. 26), na qual, não se trata de um espaço neutro, mas, contrariamente, os espaços operam com uma espécie de discurso que instituiu em sua materialidade, um sistema de valores, um conjunto de aprendizagens sensoriais e motoras e uma semiologia que recobre símbolos estéticos, culturais e ideológicos.

Ainda observando a ideia de espaço escolar, local onde são disseminados práticas e hábitos no interior da escola, o que Julia (2001) denomina cultura escolar, o mesmo afirma que "[...] a cultura escolar como um conjunto de normas que definem conhecimentos a ensinar e condutas a inculcar, e um conjunto de práticas que permitem a transmissão desses conhecimentos e a incorporação desses comportamentos [...].” (JULIA, 2001, p. 10).

Ao analisarmos essa perspectiva de espaço escolar e a cultura disseminada no interior da escola, percebemos que os ideais republicanos em busca da modernização perpassam por esses dois elementos, uma vez que se faz necessário perpetuar esse ideário, sendo que a escola, por agregar em um mesmo espaço muitas "mentes" a serem moldadas, seria o 
instrumento ideal para perpetuar a diretriz da nova política em questão. Desta maneira, o sentimento de patriotismo e de civismo serão também fortemente disseminados no âmbito escolar. A esse respeito, Souza (1999) destaca que,

\begin{abstract}
Ao tornar os eventos cívicos uma atividade escolar, o Estado faz da escola primária um instrumento de perpetuação da memória nacional. As festas escolares, diferentemente das festas do calendário social, não contrapõem o tempo livre ao tempo do trabalho, pois elas constituem tempo de atividade educativa, um tempo a aprender. (SOUZA, 1999, p. 134).
\end{abstract}

Os eventos cívicos são, de fato, um momento de congraçamento entre a escola e a sociedade, pois eles despertam no público um sentimento de amor à Pátria, respeito e, também, educam, pois, esses festejos disseminam valores e condutas que reforçam o ideário do Estado. Nessa perspectiva, os festejos cívicos fazem parte do currículo da escola, sendo uma atividade que agrega alunos, professores e direção, pois é uma manifestação cultural que dá identidade a instituição escolar. Bencostta entende que "[...] os desfiles patrióticos dos grupos escolares como transmissores de uma linguagem coletiva, capaz de expressar concomitantemente múltiplos planos simbólicos que os levam a ser identificados como uma grande festa.” (BENCOSTTA, 2006, p. 300).

Deste modo, podemos afirmar que esses eventos vão além da celebração, pois, em verdade, também tinham outras intenções, entre elas, a disseminação de conteúdos e de comportamentos associados à nova conjuntura política instaurada no país. Nessa perspectiva, podemos tomar essas festividades cívicas como parte de uma cultura escolar desenvolvida no interior das escolas, uma vez que essas atividades fazem parte do currículo escolar e que incorporam práticas distintas que envolvem vários personagens do cenário educacional, professores, alunos, corpo administrativo e diretor.

Bencostta (2004) observa ainda que as festividades cívicas incorporadas ao calendário escolar não são uma descontinuidade do tempo escolar, mas sim, são intercalados por ele e, por isso mesmo, elas sugerem a adesão e o empenho dos protagonistas, representados por professores e alunos.

Ao relacionarmos essas festas escolares com o mundo social, é possível afirmar que elas possuem uma intencionalidade, pois, se são veiculadas pela escola, certamente são instrumentos de uma política educacional vigente, com intuito de disseminar normas e valores. Nesse contexto, a escola demonstra os valores difundidos em seu interior e estende à população, por meio das festas cívicas, a fim de consolidar o modelo a ser seguido por toda a sociedade. Ribeiro Junior (1982) afirma que

A festa é uma forma de ritual, tradicional, de inculcação dos princípios pedagógicos elaborados pela cultura do povo e que forma um "habitus-de-ser-povo". Este é reforçado através de uma pedagogia implícita que mais vive do que tematiza seus princípios. A festa é uma verdadeira ação pedagógica, que integra sanções, autoridade e um modo específico de inculcação. (RIBEIRO JUNIOR, 1982, p. 43). 
Evidencia-se, deste modo, o caráter eminentemente pedagógico destes eventos cívicos, pois é possível perceber no calendário escolar, bem como em parte dos conteúdos escolares, em especial, daquele disseminado na disciplina de Educação Moral e Cívica, a incorporação de datas importantes a serem comemoradas, reforçando, assim, a conduta a ser seguida pela sociedade, no que diz respeito à questão da civilidade e do patriotismo. Segundo Cândido (2007, p. 38),

Nas festas ocorridas em instituições escolares percebe-se que a festa é para a população, já que ela participa passivamente como observadora do ritual e $d a$ população, a partir do momento que ela apreende ativamente os sentidos e significados atribuídos a cada ocasião festiva.

A festa cívica ocorre no intuito de reforçar as dimensões políticas e patrióticas, na intencionalidade de legitimar a questão do culto à ordem, importante para o desenvolvimento do ideal de modernidade e de progresso no Brasil.

\title{
AS REPRESENTAÇÕES NA IMPRENSA DAS ATIVIDADES ESCOLARES DE CUNHO CÍVICO-PATRIÓTICO.
}

No caso do presente artigo, ao longo da primeira metade do Século XX, observamos as cidades de Uberlândia e de Uberaba, ambas localizadas na região do Triângulo Mineiro, no Estado de Minas Gerais, quando foi possível perceber, sobretudo na imprensa local, a disseminação do novo contexto republicano que então se instaurava, no qual, ordem, progresso, civismo e patriotismo eram palavras importantes para a projeção da cidade no contexto nacional. Nessa direção, um pequeno fragmento de texto publicado no jornal "A Tribuna", de Uberlândia, demonstra essa preocupação,

\begin{abstract}
A ordem tem seu fundamento no caracter objetivo da invariabilidade das leis naturaes. A ordem artificial, desprezado ponto de vista subjectivo, repousa necessariamente sobre a ordem natural e resulta do conjunto das leis reaes. A correlação que se nota entre a existencia e o movimento, transportada para o campo social, se manifesta egualmente entre a ordem e o progresso. A ordem se torna, assim a condição permanente do progresso, ao passo que este constitue sempre o objectivo daquella. Emfim, não se comprehende o progresso, sinão em uma sociedade em que a ordem assume a cada passo um estado de maior perfeição. E o progresso deve ser visto como um aperfeiçoamento, na evolução da ordem. [...] Nem a ordem immovel, nem o progresso que não se funda na ordem são bastantes fecundos; pelo contrario, o mais completo ideal se encontra na ordem que evolue e assim progride. Ahi os dois ideaes se harmonizam numa formula única: ordem e progresso. (CAMPOS, 1921, p. 1).
\end{abstract}

Nessa perspectiva, a escola deveria ocupar o papel central nas pequenas cidades que começavam a se desenvolver, a fim de propagar esses ideais republicanos. As festas cívicas realizadas pelas escolas também eram importantes para reforçar esses ideais. Tais eventos contemplavam participação ativa de seus alunos, com extensas programações, incluindo 
discursos, apresentações artísticas e esportivas. As festividades desenvolvidas no espaço escolar eram capazes de mobilizar todos os seus atores, alunos, professores, direção e corpo administrativo. É nesse contexto que trazemos aqui o exemplo de duas escolas de nível secundário das cidades de Uberlândia e Uberaba, que nasceram da iniciativa da sociedade civil e que marcaram fortemente o contexto escolar de suas cidades no que diz respeito às festividades cívicas e que foram amplamente divulgadas por meio da imprensa local ${ }^{3}$.

Em Uberlândia, o antigo Gymnásio Mineiro de Uberabinha, atual Escola Estadual de Uberlândia, instituição de ensino secundário, foi referência tanto em relação ao ensino quanto na participação das atividades cívicas da cidade. Nessa direção, o jornal "O Repórter”, em uma reportagem sobre a Semana da Pátria, datada de 12 de setembro de 1942, elogiava as magníficas demonstrações de civismo efetivadas na cidade pelas escolas em geral:

Foi uma festa de singular esplendor a concentração da juventude uberlandense no dia 5 corrente, na Praça Benedito Valares, ponto escolhido de partida para o desfile em conjunto pelas ruas da cidade. Ao ritmo dos tambores, ao toque das marchas pelas bandas de corneta, a mocidade sadia marchou conduzindo triunfalmente dezenas de bandeiras brasileiras. Na apoteose deslumbrante e emocional da Pátria, que ultrajada ergue-se exigindo a revide, os colegiais significavam bem, em sua sadia vibração cívica, a alma do Brasil consciente da vitória e destemido as provocações dos bárbaros sequiosos de demolir, no mundo, a milenar civilização que construiu monumentos imperecíveis de cultura, e de que nasceram as nações livres no fulgor das democracias. Nunca assistimos, como na hebdomada votiva de comemorações históricas na nossa nação maravilhosa, espetáculo de tão empolgante beleza, índice cristalino que nos deu a visão do trabalho de brasilidade que se pratica em nossos educandários. Nem se podia selecionar ou distinguir qual estabelecimento que melhor se preparou para essa jornada de culto ao Brasil, pois em todos percebia-se no conjunto e nos detalhes, o Maximo capricho na organização dos seus quadros discentes. Rapazes e moças, com o mesmo garbo e uniformidade de marcha deixavam transparecer a sinceridade que os inspirava naquela cerimônia de nobreza impar. E os aplausos do público numeroso e alegre, nas sacadas dos prédios e de um lado e de outro nos passeios das ruas anunciadas para o intinerario do desfile escolar, diziam bem alto da impressão cansada por essa parada das nossas casas de ensino no animo de todos os que tiveram a gratissima felicidade de presencia-la. Cabem nesta noticia as melhores felicitações aos diretores, professores e alunos de estabelecimentos que figuram nessa festa, cujo profundo sentido espiritual enaltece ainda mais as tradições seculares de Minas Gerais e do Brasil. (O REPÓRTER, 1942b).

Percebe-se que no artigo publicado há uma grande euforia por parte do jornal, enaltecendo a juventude que participou do evento, vangloriando o patriotismo, que naquele momento era o máximo da inspiração de moças e moços que representavam suas escolas. $\mathrm{E}$ essa inspiração era transmitida àqueles que ali estavam para assistir e que retribuíam com aplausos pelo brilhante espetáculo.

$\mathrm{Na}$ cidade de Uberaba, por sua vez, o Colégio Triângulo Mineiro, outro estabelecimento de ensino secundário também tinha forte participação nas festividades cívicas da cidade. O jornal "Lavoura e Comércio" destacou o "brilhantismo" daquele "[...] novel e já 
tão renomado educandário", segundo esse jornal os alunos “[...] impressionaram vivamente a toda a grande massa popular" que comparecera à Praça de Esportes, em uma prova do compromisso do diretor com a pátria brasileira. (LAVOURA E COMÉRCIO, 1944).

Em ambos os casos, é possível perceber a forte participação tanto de alunos nessas atividades desenvolvidas pelas escolas, quanto da sociedade local, que prestigiava estes eventos.

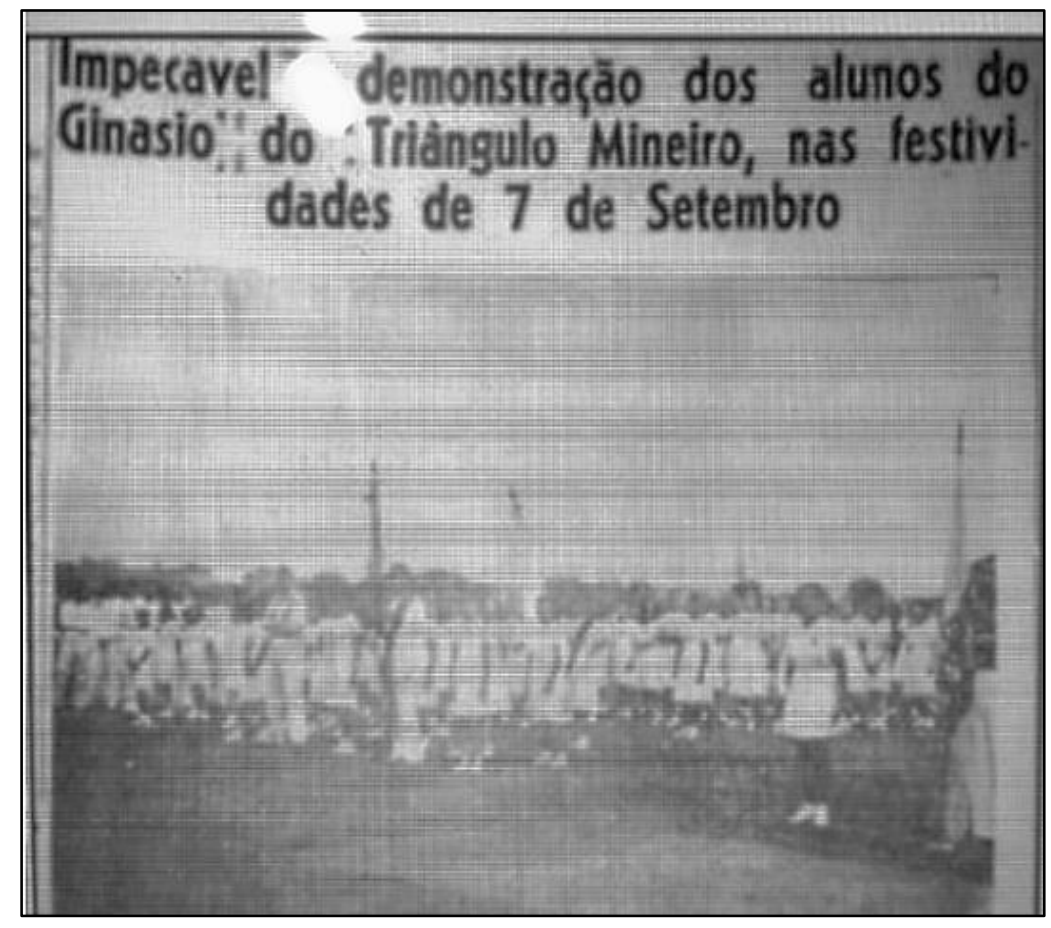

Fotografia 1 - Notícia sobre o Ginásio Triângulo Mineiro no Sete de Setembro Fonte: Lavoura e Comércio, 1944.

O Colégio Triângulo Mineiro, pelo que se observou na iconografia encontrada na Secretaria Regional de Ensino de Uberaba e no Memorial Mário Palmério, bem como pelos conteúdos disseminados nos jornais da época, era perceptível a liderança de seu diretor Mário Palmério a frente desses eventos cívicos.

Segundo registros veiculados pelo jornal "Lavoura e Comércio", o referido diretor, além das datas oficiais, estabeleceu no colégio, que o centenário de Castro Alves fosse comemorado e o dia de Tiradentes também. Tal fato foi noticiado e apreciado pelo referido jornal destacando que essas iniciativas demonstravam o "apreço" de Mário Palmério por "[...] todas as datas nacionais" e pelo "[...] culto dos homens que souberam engrandecer a pátria brasileira." (LAVOURA E COMÉRCIO, 1947, p. 4). 


\section{Revista HIIS'TNIDBR (On-line}

Artigo

doi: $10.20396 /$ rho.v18i1.8651600

O espírito patriótico incorporado pela elite local da cidade de Uberaba como nova diretriz política, motivou ainda mais esses eventos na cidade. O jornal "Lavoura e Comércio" demonstra isso no texto que segue,

Os trezentos e tantos moços e moças, que sob o comando pessoal do Sr. Prof. Mário Palmério, desfilam pelas nossas principais ruas e que foram em seguida, homenagear nossas autoridades [...] deram, com sua magnífica apresentação, a demonstração cabal do esforço que se desenvolve no Ginásio Triângulo Mineiro, em prol da educação cívica de nossa juventude. (LAVOURA E COMÉRCIO, 1944).

As festas cívicas davam grande visibilidade às escolas, pois era uma forma de serem mostrados e de reafirmados perante a sociedade, suas ideias e valores, importantes na constituição da cultura da cidade. Segundo Silva (2009, p. 3):

As festas, entre outras coisas, acabaram constituindo um modo de construir e difundir referências e símbolos nacionais não só entre os estudantes e professores como também a sociedade de modo geral, integrando, assim, a memória coletiva. Hinos, hasteamento da bandeira e pavilhão escolar constituíam atividades decisivas na constituição da memória coletiva oficial.

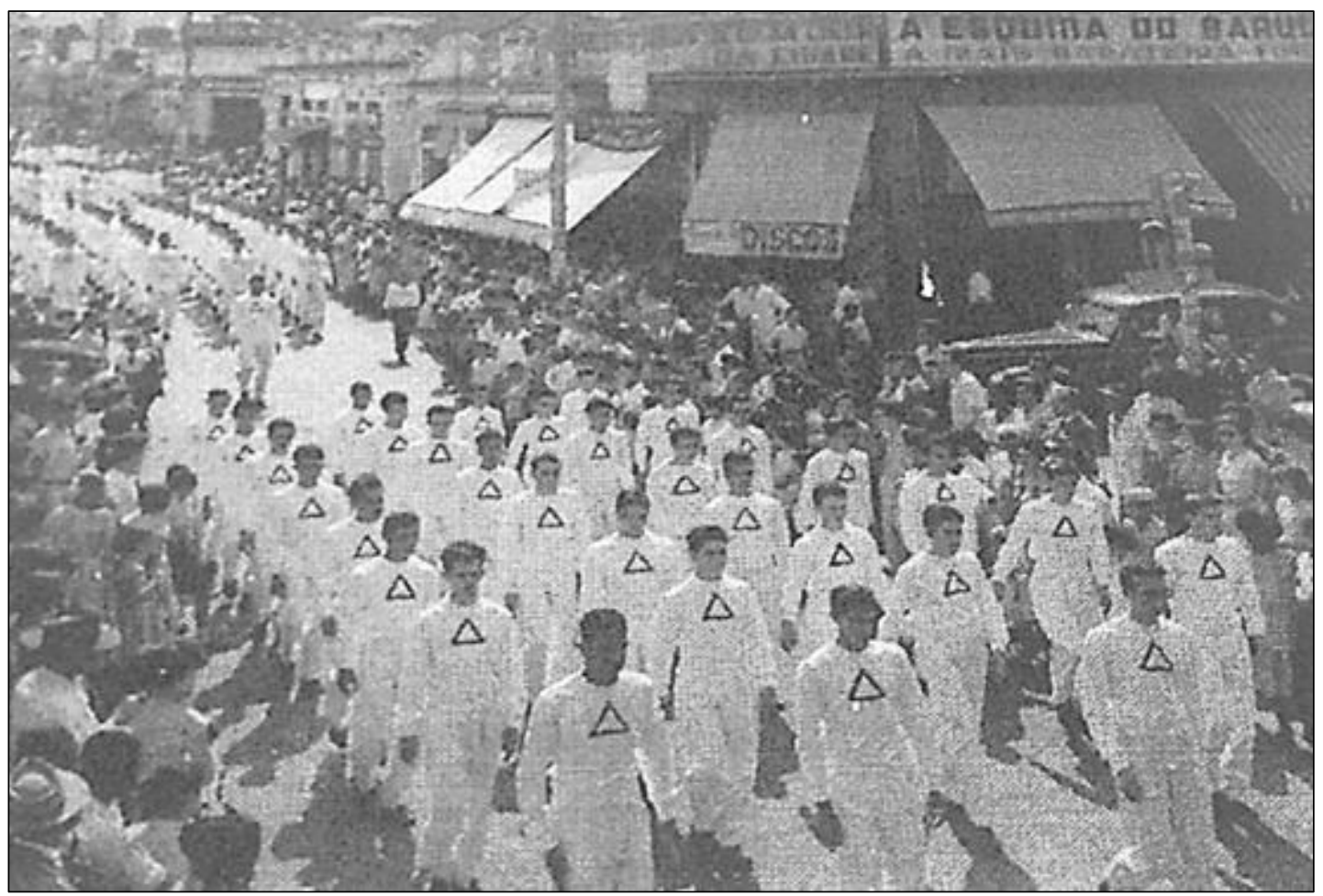

Fotografia 2 - Parada Cívica Colégio Triângulo Mineiro, em Uberaba, Minas Gerais Fonte: Memorial Mário Palmério, Universidade de Uberaba (s/d). 


\section{Revista HIIS'TNIDBR On-lime}

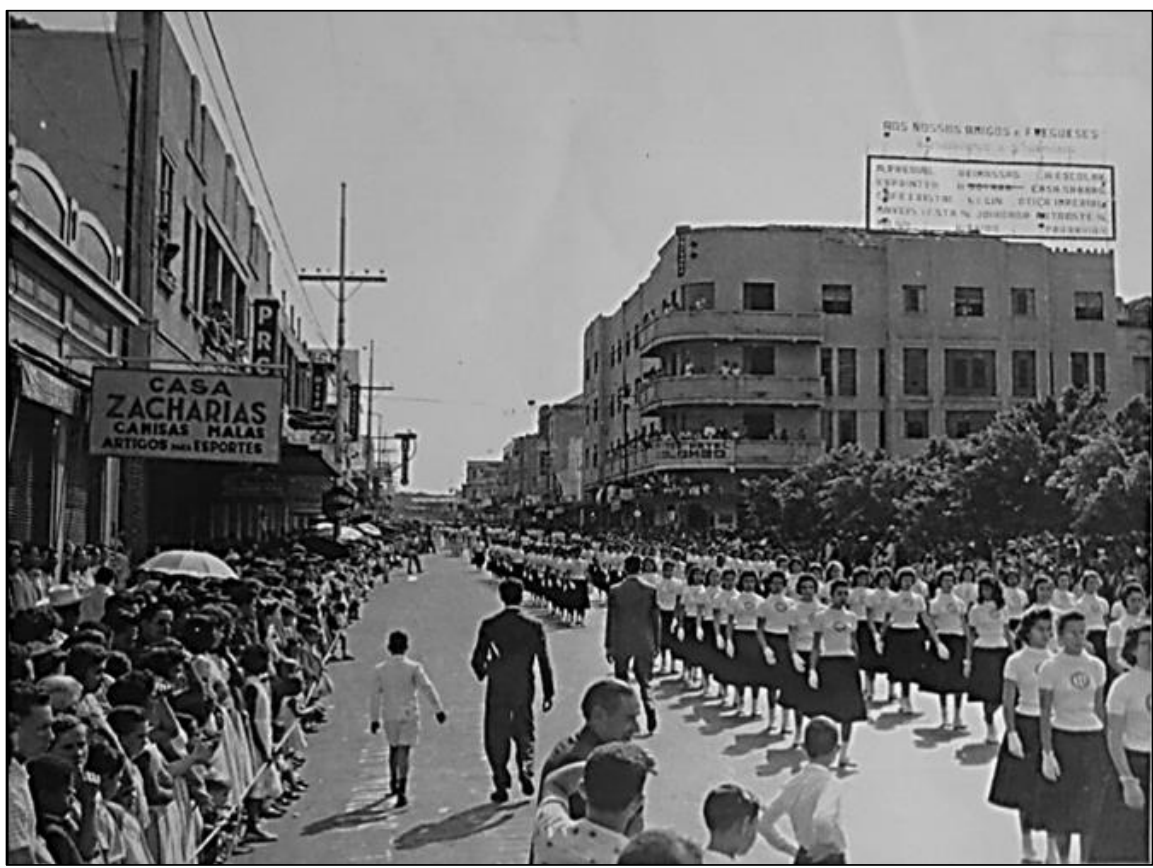

Fotografia 3 - Desfile do Sete de Setembro pelo Colégio Estadual de Uberlândia. Fonte: Acervo da Escola Estadual de Uberlândia (s/d).

Nas fotografias 2 e 3 é possível perceber a quantidade de pessoas ladeando as avenidas onde aconteciam os desfiles relacionados às paradas cívicas, em especial o Sete de Setembro. Essas imagens demonstram a forte participação da sociedade local. Assim, homens e mulheres aglomeravam-se atrás dos cordões de isolamento, em Uberlândia, pessoas no alto de pequenos edifícios também contemplam o desfile escolar. O impacto na imprensa local nesses eventos consolidava ainda mais a importância dos eventos cívicopatrióticos, com destaque para o papel da escola representada pela juventude, como uma forma de fortalecer os ideais políticos de uma época. O artigo publicado em Uberlândia ilustra este fato:

Cabe ao Gymnásio Mineiro, sem duvida, destacada referencia quanto ao relevo da parte de seu programa nas comemorações da Semana da Pátria. Com efeito, aquele reputado educandário oficial, com a orientação didática que lhe imprimiu seu atual Reitor, o infatigável educador professor Oswaldo Vieira Gonçalves, iniciou desde o dia primeiro as suas expansões de patriotismo no período destinado a evocação do nosso passado e das nossas glórias, na fundação da nacionalidade livre com a resolução de Pedro I as margens históricas do Ipiranga. [...] Foi este itinerário percorrido pelos condutores da Tocha, símbolo de fé e de devotamento do coração da mocidade a grande pátria: - partida do Gymnásio, pela Avenida Cipriano Del Fávero até a esquina da Rua Getúlio Vargas, por esta à Avenida João Pinheiro, desta à Avenida João Pessoa, Avenida Floriano Peixoto, praça Cel. Carneiro, Rua Tiradentes, Vigário Dantas e novamente o Gymnásio. [...] Os números executados pelas alunas, que foram treinadas e receberam instrução física da competente e dedicada professora Dona Luiza Ribeiro Miranda, causaram ótima impressão na assistência, pela segurança e magnífica execução, recebendo fortes aplausos. (O REPÓRTER, 1942a). 


\section{CONSIDERAÇÕES FINAIS}

Depreende-se do que aqui foi apresentado que a imprensa, a partir dos eventos cívicopatrióticos realizados em instituições escolares, teve um papel muito importante na incorporação pela população de ideologias de Estado disseminadas por meio da educação escolar. Além disso, também ficou demonstrado que a imprensa constitui uma fonte importante para a construção de interpretações relacionadas à compreensão de aspectos histórico-educacionais de uma época

Foi possível perceber como as festividades de cunho cívico patriótico, a partir da instituição escolar e da imprensa local, mobilizavam a cidade e sua população, com a imprensa podendo ser considerada como corresponsável na construção do patriotismo, por meio da divulgação e dos registros que diziam respeito a estes eventos na cidade.

Em síntese, os eventos cívico-patrióticos, verdadeiras festividades que envolviam escolas, imprensa e a população das cidades, além de movimentarem a vida das pessoas em seus municípios também propagavam um ideal político, ou seja, disseminavam sentimentos patrióticos alinhados aos ideais de Estado, na direção de construir uma identidade e uma consciência coletiva. A imprensa, nesse sentido, contribuía para que essas representações de Ordem e de Progresso fossem reforçadas e perpetuadas nas mentalidades, o que, sem dúvida, ajuda a compreender o que movia as mentalidades em uma época, mas, também, reforça o entendimento da imprensa como sendo uma fonte extremamente importante para os historiadores de modo geral e para os historiadores da educação de modo particular.

\section{REFERÊNCIAS}

BASTOS, M. H. C. Espelho de papel: a imprensa e a história da educação. In: ARAUJO, J. C. S.; GATTI JUNIOR, D. (Org.). Novos temas em história da educação brasileira: instituições escolares e educação na imprensa. Campinas, SP: Autores Associados, 2002. p. 151-174.

BENCOSTTA, M. L. A. Desfiles patrióticos: cultura cívica nos grupos escolares de Curitiba (1903-1971). In: CONGRESSO BRASILEIRO DE HISTÓRIA DA EDUCAÇÃO, 3., 2004, Anais eletrônicos... Curitiba: PUC-PR, 2004. Disponível em: <http://sbhe.org.br/novo/congressos/ cbhe3/Documentos/Individ/Eixo1/034.pdf>. Acesso em: 20 mar. 2015.

BENCOSTTA, M. L. A. Desfiles patrióticos: memória e cultura cívica dos grupos escolares de Curitiba (1903-1971). In: VIDAL, D. G. (Org.). Grupos escolares: cultura escolar primária e escolarização da infância no Brasil (1893-1971). Campinas, SP: Mercado das Letras, 2006. p. 299-321.

CAMPOS, J. Ordem e Progresso. A Tribuna, Uberabinha/MG, 10 abr. 1921, ano 2, n. 83, p. 01. 1921. 
CÂNDIDO, R. M. Culturas da escola: as festas nas escolas públicas paulistas (18891930). 2007. Dissertação (Mestrado em Educação) - Faculdade de Educação, Universidade de São Paulo, São Paulo, 2007.

DESFILE do Sete de Setembro pelo Colégio Estadual de Uberlândia. Uberlândia/MG. Acervo da Escola Estadual de Uberlândia. 1 fotografia.

ESCOLANO BENITO, A. A arquitetura como programa. Espaço-escola e currículo. In: VINÃO, F. A.; ESCOLANO BENITO, B. A. (Org.). Currículo, espaço e subjetividade: a arquitetura como programa. Rio de Janeiro: DP\&A, 1998. p. 19-57.

GATTI, G. C. do. V. A escola e a vida na cidade: o Gymnásio Mineiro de Uberlândia (1929-1950). Uberlândia, MG: Ed. da EDUFU, 2013.

JULIA, D. A Cultura escolar como objeto histórico. Revista Brasileira de História da Educação, v. 1, n. 1, p. 9-43, jan./jun. 2001.

LAVOURA E COMÉRCIO. Notícia sobre o ginásio Triângulo Mineiro no Sete de Setembro. Uberaba/MG. 1944. 1 fotografia.

LAVOURA E COMÉRCIO, Uberaba/MG. 08 set. 1944.

LAVOURA E COMÉRCIO, Uberaba/MG. 21 abr. p. 4, 1947.

MELO, J. M. de. A opinião no jornalismo brasileiro. 2. ed. Petrópolis: Vozes, 1994.

NÓVOA, A. A Imprensa de educação e ensino: concepção e organização do repertório português. In: CATANI, D. B.; BASTOS, M. H. C. (Org.). Educação em Revista. A imprensa periódica e a história da educação. São Paulo: Escrituras, 1997. p. 11-31.

O REPÓRTER. Uberlândia/MG. 05 set. 1942a.

O REPÓRTER. Uberlândia/MG. 12 set. 1942b.

PARADA Cívica Colégio Triângulo Mineiro, em Uberaba, Minas Gerais. [S.D]. Acervo Mário Palmério. Universidade de Uberaba. 1 fotografia.

RIBEIRO JUNIOR, J. C. N. A Festa do povo: pedagogia de resistência. Petrópolis, RJ: Vozes, 1982.

SILVA, V. C. Comemorações Cívicas como Instituidoras da Unidade Nacional no Estado Novo. In: SEMANA DE ENSINO DE HISTÓRIA DA UERN, 1., 2009 Anais eletrônicos... Mossoró/RN: URCA, 2009. Disponível em: <http://isemanadeensinode historia.xpg.uol.com.br/arquivos/trabalhos/12.htm>. Acesso em: 20 mar. 2015.

SOARES, E. A. L. S. O Colégio Triângulo Mineiro e o ensino secundário em Uberaba/MG, entre 1940 e 1960. 2015. Dissertação (Mestrado em Educação) Universidade Federal de Uberlândia, Minas Gerais, 2015. 
SOUZA, R. F. de. Tempos da Infância, tempos de escola: a ordenação do tempo escolar no ensino público paulista (1892-1933). Educação e Pesquisa, v. 25, n. 2, p. 127-143, jul./dez. 1999.

VIDAL, D. G.; CAMARGO, M. J. G. de. A imprensa periódica especializada e a pesquisa histórica: estudos sobre o boletim de educação pública. Revista Brasileira de Estudos Pedagógicos, v. 73, n. 175, p. 407-430, set./dez. 1992.

Notas

${ }^{1}$ Doutora em Educação, com estágio de pós-doutorado concluído no Programa de Pós-Graduação em Educação da Universidade Federal de Uberlândia (UFU). Professora do Programa de Pós-Graduação em Educação da Universidade de Uberaba (UNIUBE). Beneficiária do Edital Universal da Fapemig. Email:giseli.vale.gatti@gmail.com.

${ }^{2}$ Doutor em Educação pela Pontifícia Universidade Católica de São Paulo (PUC-SP), com estágio de pósdoutorado concluído na Faculdade de Educação da Universidade de São Paulo (FEUSP). Professor Titular de História da Educação na Universidade Federal de Uberlândia (UFU). Bolsista de Produtividade em Pesquisa do CNPq. Beneficiário do Programa Pesquisador Mineiro da Fapemig. E-mail: degatti@ufu.br

${ }^{3}$ Para conhecer melhor a história das duas escolas mencionadas neste artigo recomenda-se as seguintes leituras: GATTI, Giseli Cristina do Vale. A escola e a vida na cidade: o Gymnásio Mineiro de Uberlândia (19291950). Uberlândia, MG: EDUFU, 2013. e, SOARES, Edilene Alexandra Leal Soares. O Colégio Triângulo Mineiro e o Ensino Secundário em Uberaba/MG, entre 1940 e 1960. 2015. Dissertação (Mestrado em Educação) - Universidade Federal de Uberlândia, Minas Gerais, 2015.

Submetido em: 02/02/2018

Aprovado em: 24/03/2018

Publicado em: 27/03/2018 